\title{
Uma discussão de oposições binárias nos Functional Requirements for Subject Authority Data (FRSAD)
}

Suellen Oliveira Milani

Estagiária de Pós-Doutorado em Ciência da Informação Universidade Estadual Paulista. Bolsista PNPD/CAPES

http://dx.doi.org/10.1590/1981-5344/2732

Como são poucos os estudos brasileiros que assumem declaradamente seus posicionamentos sobre as biases, este artigo propõe-se a apresentar uma discussão crítica sobre as biases na representação de assunto a partir dos Functional Requirements for Subject Authority Data: A Conceptual Model (FRSAD). Para esse exercício, adotamos uma postura epistêmica pós-estruturalista, pois não estamos em busca de verdades universais, mas de uma outra maneira de entender a representação de assunto e os substitutos documentais construídos pelos bibliotecários. Elegemos o método Desconstrução (OLSON, 1996) para descentralizar a oposição binária neutralidade versus interesses especiais, isto é, de um lado temos a crença do bibliotecário em evitar a interferência de seus valores morais na busca de uma suposta imparcialidade e, do outro, a necessidade deste mesmo profissional realizar julgamentos de valor visando melhor representar comunidades usuárias específicas. Os binários foram descentralizados a partir dos FRSAD ressaltando-se as relações de poder percebidas, assim como as premissas e as presunções subjacentes a elas.

Palavras-chave: Desconstrução; Oposição binária; Neutralidade na representação de assunto; Interesses especiais na representação de assunto; Requisitos Funcionais para Dados de Autoridade de Assunto (FRSAD). 


\title{
A binary opposition discussion on the Functional Requirements for Subject Authority Data (FRSAD)
}

\begin{abstract}
Considering that only a few of the Brazilian studies assumes their positions on biases, this paper proposes to present a critical discussion about biases in subject representation through the Functional Requirements for Subject Authority Data (FRSAD): A Conceptual Model. For this exercise, we adopted a post-structuralist epistemic stance once we are not searching for universal truths, but for another way to understand subject representation and the document surrogates constructed by librarians. Deconstruction (OLSON, 1996) was the method used to descentralize the binary opposition neutrality versus special interests. Thus, we have on one hand the librarian's belief to avoid interference from his moral values while pursuing a supposed impartiality and, on the other hand, her/his need to make value judgments to better represent specific communities of users. Binaries were descentralized using the FRSAD and power relations as well as underlying assumptions and presumptions inherent to them were highlighted.
\end{abstract}

Keywords: Deconstruction; Binary opposition; Neutrality in subject representation; Special interests in subject representation; Functional Requirements for Subject Authority Data (FRSAD).

Recebido em 06.03.2016 Aceito em 03.05.2017

\section{Introdução}

Bias pode ser traduzida por viés, inclinação ou direcionamento e integra um importante tópico de assunto a ser discutido no campo da organização da informação, mais especificamente na representação de assunto, e merece ser analisado profundamente uma vez que as biases podem ocorrer em múltiplas instâncias: a) na atuação do bibliotecário, b) nos instrumentos de representação de assunto, c) nos substitutos documentais e d) no próprio documento, como já salientaram Milani, Guimarães e Olson (2014).

São considerados como biases na representação de assunto os direcionamentos presentes nos substitutos documentais e nos instrumentos de representação de assunto que fomentem qualquer 
prejuízo a uma determinada comunidade de usuários; por vezes, esses direcionamentos visam garantir especificidade às comunidades por meio da representação de assunto, no entanto, podem revelar inclinações ou tendenciosidades evocando crenças e princípios de quem construiu o substituto documental ou o instrumento de representação de assunto em questão. Essas tendenciosidades podem, ainda, reforçar preconceitos ou promover desvios na representação de assunto causando efeitos danosos aos usuários da biblioteca que não pertencem às comunidades dominantes. Quando presente no documento a ser analisado, o bibliotecário tomará uma decisão ética sobre a maneira pela qual negociará com essa bias.

Percebemos que a literatura de Biblioteconomia e Ciência da Informação vem discutindo tópicos relacionados às biases ${ }^{1}$ na representação de assunto, mas ainda de forma incipiente. Sistematizações como as de Olson e Schlegl (2001) e de Milani (2015) sinalizam que a presença de biases negativas ou positivas na representação de assunto não é algo que possamos evitar e, partindo dessa premissa, a neutralidade da classificação e da indexação, bem como a imparcialidade dos esquemas de classificação e das linguagens de indexação passam a configurar-se como crenças que não correspondem à realidade. Como são poucos os estudos que assumem declaradamente os seus posicionamentos sobre as biases na representação de assunto, foi necessário traçar uma metodologia que nos permitisse investigar esse fenômeno mais profundamente. Para tanto, perguntamo-nos: enquanto modelagem conceitual que pretende amparar a representação de assunto, os Functional Requirements for Subject Authority Data: A Conceptual Model (FRSAD) contêm biases?

A proposta deste artigo é apresentar uma discussão crítica sobre as biases na representação de assunto a partir dos FRSAD de modo a: a) apresentar as questões auto evidentes e retornar aos postulados básicos nos quais a representação de assunto está estabelecida, e b) identificar as principais áreas do conhecimento que a representação de assunto evoca ressaltando as relações de poder percebidas, assim como as premissas e as presunções subjacentes a elas. Tal reflexão ofereceria elementos teóricos para as pesquisas sobre a atuação ética do bibliotecário no campo da organização da informação.

\footnotetext{
1 Cumpre destacar a nossa opção por manter o termo original bias(es) em inglês por abranger, em língua portuguesa, as conotações negativas de tendência, inclinação ou desvio e as conotações positivas de direcionamento ou viés. O termo inglês bias na área de organização da informação é polissêmico e a origem e consolidação da discussão teórica sobre as biases ocorreram na literatura de língua inglesa, seguidas de uma discussão na literatura em língua espanhola por meio do termo sesgo. De acordo com Barité (2011, p. 241), sesgo emerge como área problema em diferentes textos relacionados às garantias literária, de usuário, cultural, acadêmica e organizacional, figurando como motivo de preocupação para os responsáveis pelos vocabulários controlados "[...] por causa das suas implicações em relação à representação de valores universais, da utilização de terminologia 'politicamente correta' e da admissão de valores e expressões de culturas locais e minorias ou grupos sociais negligenciados $[\ldots]^{\prime \prime}$
} 


\section{Metodologia e identificação da oposição binária}

Para empreender uma reflexão sobre as biases na representação de assunto realizamos uma exaustiva revisão da literatura internacional e um exercício aplicado. Para esse exercício, adotamos uma postura epistêmica pós-estruturalista pois entendemos que cada domínio do conhecimento constrói as suas próprias formas simbólicas, e não uma verdade singular, e essas formas simbólicas refletem os discursos que as permeiam; 0 domínio do conhecimento estudado é o da representação de assunto.

$\mathrm{Na}$ busca por um método que oferecesse legitimidade à nossa leitura e convergisse com o pós-estruturalismo, encontramos a Desconstrução aplicada por Olson (1996) na área de Biblioteconomia e Ciência da Informação. Ao aplicarmos esse método, esperávamos entender o porquê de as coisas estarem construídas da maneira como estão, para, então, oferecermos uma possibilidade de resposta, e não uma resposta singular.

As oposições binárias são o foco do processo de desconstrução. A desconstrução "[...] mostra que as oposições binárias são construídas, não inatas. Elas são constituídas por oposições aparentemente opostas [...]" (OLSON, 1996, p. 76).

Oposição binária, ou binariedade, significa a combinação de duas coisas, um par, um dualismo. É importante dizer que:

[a] primeira referência à binariedade foi feita pelo linguista estruturalista francês Ferdinand de Saussure, que afirma que os signos não têm significados por meio da simples referência a objetos reais, mas por meio da sua oposição a outros signos. Cada signo apresenta em si mesmo a função de um binário entre o significante, o 'referente' ou imagem acústica da palavra, e o significado. Saussure assegura que, embora a conexão entre o significante e o significado seja arbitrária, (isto é, na natureza não há nenhuma necessidade da existência de uma ligação entre a palavra 'cachorro' e o significado cachorro), uma vez que ela é estabelecida, a conexão torna-se fixa para todo mundo que fala aquela língua (ASHCROFT; GRIFFITHS; TIFFIN, 2007, p. 18).

Os autores explicam que, apesar de os signos assumirem significados a partir de suas diferenças em relação a outros signos, as oposições binárias consistem na forma de diferença mais extrema possível. As oposições binárias compõem um sistema binário que, por sua vez, contribui com a construção cultural da realidade;

[o] problema desses sistemas binários [sol/lua; homem/mulher; nascimento/morte; preto/branco] é que eles suprimem espaços ambíguos ou intersticiais entre as categorias opostas, de modo que qualquer área de sobreposição que possa surgir [digamos, entre as categorias mulher/homem, criança/adulto ou amigo/inimigo] torna-se impossível de acordo com a lógica binária e uma área tabu no 
contexto de experiência social (ASHCROFT; GRIFFITHS; TIFFIN, 2007, p. 18).

As oposições binárias figuram como verdadeiras sementes no processo de desconstrução, principalmente ao realçarmos que cada binário representa uma relação hierárquica entre um conceito dominante e um dominado. Quando identificamos os binários, "[...] o foco muda para a descoberta de traços do outro, o conceito subordinado, em textos relevantes" (OLSON; FOX, 2012, p. 92).

A desconstrução revela

[...] o outro e esvazia a hierarquia. O outro está frequentemente escondido textualmente nas notas de rodapé, à parte ou implícito na definição do dominante. A obscuridade da fronteira entre o dominante e o outro oculta a existência do outro e, portanto, a íntima relação dos dois (OLSON, 2001, p. 3).

A desconstrução "[...] não inverte os binários simplesmente ou substitui a estrutura antiga por uma nova estrutura. De preferência, ela mostra a estrutura antiga, a estrutura dominante, o núcleo, enquanto uma realidade construída" (OLSON, 2001, p. 5). Assim, para realizarmos uma desconstrução, podemos nos guiar por três etapas dinâmicas e de fronteiras tênues:

a) identificação das oposições binárias;

b) descentralização das oposições binárias;

c) transcendência das oposições binárias.

Para realizar essas etapas, enquanto pesquisadores assumimos o papel de sujeito cognoscente, mantendo, assim, um posicionamento bem próximo ao nosso objeto de estudo. Essa decisão foi tomada considerando que este seria o paradigma epistemológico que beneficiaria este estudo, afinal "[c]ada modalidade de conhecimento pressupõe um tipo de relação entre sujeito e objeto e, dependentemente dessa relação, temos conclusões diferentes" (SEVERINO, 2007, p. 108).

Durante a revisão de literatura apresentada em Milani (2015), construímos um conjunto de oposições binárias que ilustrariam de forma defensável os artigos lidos a partir da técnica de close reading ${ }^{2}$. Ao sintetizarmos esse conjunto, construímos a oposição binária neutralidade versus interesses especiais e, para descentralizá-la, elegemos trechos significativos dos FRSAD.

Os referidos trechos significativos dos FRSAD foram comparados com definições extraídas do Dicionário Aulete. Essas definições foram

\footnotetext{
${ }^{2}$ Foram seguidas as orientações fornecidas por McClennen (2001) e Kain (1998). O objetivo da aplicação dessa técnica é a observação dos fatos e detalhes de um texto ao "lê-lo mais de perto."
} 
utilizadas toda vez que percebemos que o leitor se beneficiaria desse recurso. Essa técnica é chamada iteração e consiste em tirar o "texto original" do seu contexto e apresentar definições e significados desse mesmo texto, de modo a identificar significados presentes nas entrelinhas. Assim, a duplicidade presente no discurso será realçada, ou seja, as diferentes definições mostrarão que os textos, as escritas e as palavras são polissêmicos, e que "[...] a interpretação padronizada dos significados dentro de uma comunidade de conhecimento particular, por exemplo, de estudiosos, é apenas um limite arbitrário imposto à escrita, que nem sempre obtém êxito em limitar os significados" (CALÁS; SMIRCICH, 1991, p. 569).

A análise dos trechos extraídos dos recortes textuais e das definições extraídas do dicionário, ou seja, a intertextualização, nos ofereceu os argumentos necessários para explicar os binários e identificar possíveis premissas e presunções que têm permeado a área de representação de assunto a partir dos FRSAD.

Assim, para descentralizarmos uma oposição binária, nós a desestabilizamos "[...] revertendo a relação hierárquica entre suas duas partes. O resultado será que o dominante não estará mais no centro e os outros nas margens" (OLSON, 2001, p. 4).

A transcendência das oposições binárias consistiria na apresentação de uma sugestão ou um ponto de partida que negociaria os limites das oposições binárias identificadas e examinadas nas etapas anteriores. Essa etapa é opcional, isto é, deverá ser inserida ou não na pesquisa de acordo com os objetivos estabelecidos e, por isso, não foi explorada pelo exercício ora apresentado.

Para negociar os limites das oposições binárias, a pesquisadora Hope Olson tem adotado o conceito de filosofia do limite desenvolvido por Drucilla Cornell o qual "[...] focaliza as fronteiras construídas ou limites entre o dominante e o outro como local para negociar-se uma relação diferente entre os dois" (OLSON, 2001, p. 5). A autora acredita que, ao invés de criarmos novos padrões de organização da informação, deveríamos seguir as orientações de Cornell (1992) e desenvolver techniques $^{3}$ que tornem os limites dos nossos sistemas de informação permeáveis.

\section{Discussão: descentralização da oposição binária}

Os FRSAD foram publicados em 2010 pela International Federation of Library Associations and Institutions (IFLA) com o objetivo de oferecer orientações sobre como representar os assuntos dos documentos com foco nas necessidades dos usuários. Essas diretrizes visam atingir um caráter referencial internacional e não se configuram como uma norma, padrão ou instrumento para a representação de assunto. É importante

\footnotetext{
${ }^{3}$ Mantivemos o termo em francês para preservar o significado do conceito, que engloba técnicas e tecnologias. Olson (2001) explica que essas techniques poderiam ser construídas a partir de trabalhos notáveis e contínuos de identificação de limites os quais trariam benefícios locais, parciais e temporários.
} 
ressaltar que a nossa autoridade para discutir esse modelo conceitual advém do próprio texto dos FRSAD. No decorrer da discussão, pretendemos ressaltar as relações de poder percebidas, assim como as premissas e as presunções subjacentes a elas.

Da expressão foco nas necessidades dos usuários emanam conceitos como igualdade, universalidade e multiculturalismo. Quando falamos em igualdade, universalidade e multiculturalismo estamos tratando de uma presunção da Biblioteconomia que denominamos neutralidade. Em contrapartida, o binário interesses especiais evoca conceitos como equidade, diversidade e diferenças.

\subsection{Espaço institucional no qual o discurso fundamenta suas declarações}

Na página inicial do seu website, a IFLA declara-se como "[...] o principal grupo internacional que representa os interesses dos serviços informacionais, das bibliotecas e de seus usuários. Ela é a voz global da profissão de biblioteconomia e informação" (IFLA, 2013).

Fundada em uma conferência na Escócia em 1927 e registrada na Holanda em 1971, a IFLA é uma organização internacional, nãogovernamental e sem fins lucrativos que conta com mais de 1500 membros em aproximadamente 150 países. Seus objetivos consistem em promover o fornecimento e prestação de serviços informacionais e biblioteconômicos de alto padrão, estimular um amplo entendimento do valor desses serviços e representar os interesses de seus membros em todo o mundo ${ }^{4}$. Para tanto, a IFLA define seu núcleo axiológico nos seguintes termos:

1) Apoio aos princípios de liberdade de acesso à informação, ideias e obras da imaginação e liberdade de expressão conforme descrito no Artigo 19 da Declaração Universal dos Direitos Humanos;

2) Crença de que as pessoas, comunidades e organizações necessitam de acesso universal e equitativo à informação, ideias e obras da imaginação para seu bem-estar social, educacional, cultural, democrático e econômico;

3) Convicção de que oferecer serviços biblioteconômicos e informacionais de alta qualidade contribui para garantir esse acesso;

4) Compromisso em viabilizar que todos os membros da Federação possam participar e beneficiar-se de suas atividades independentemente de nacionalidade,

\footnotetext{
${ }^{4}$ Os membros da IFLA são provenientes de associações nacionais, internacionais e institucionais e têm direito a voto nas eleições e reuniões, enquanto os afiliados pessoais, que são os profissionais liberais da área, não o têm. Muitas parcerias foram estabelecidas com corporações e também com organizações não governamentais durante esses anos de atuação da IFLA. A organização se mantém com o pagamento da anuidade de seus membros, venda de suas publicações, doações de corporações e financiamentos de agências governamentais.
} 
deficiência, origem étnica, gênero, localização geográfica, língua, filosofia política, raça ou religião (IFLA, 2013, grifos nossos).

O conjunto de valores éticos que a IFLA designa como sendo seu núcleo axiológico é amplo, visando englobar as principais máximas que envolvem a Biblioteconomia. No entanto, ao adotar essa perspectiva abrangente, ela priva seus leitores de uma reflexão importante sobre as necessidades informacionais dos usuários da biblioteca.

Para fundamentar nosso argumento, iniciamos focalizando os termos contidos no item 2, no qual a IFLA afirma sua crença de que as pessoas, comunidades e organizações necessitam de acesso universal e equitativo à informação.

Universal: 1. Que compreende todas as coisas, que se estende a tudo ou a todos, que é aplicável a tudo (sufrágio universal); GERAL. [...] 5. Que não é específico; que atende a diversas necessidades, situações etc. (padrão universal). 6. Que tem o caráter de generalidade abstrata, que compreende tudo; que se estende a tudo ou a todos, que é aplicável a tudo; ABSOLUTO (DICIONÁRIO..., 2014).

Quando se tem como objetivo fomentar o bem-estar social, educacional, cultural, democrático e econômico dos usuários possibilitando a eles o acesso à informação, o termo universal torna-se inapropriado. Os usuários não se beneficiariam de acessos com caráter de generalidade abstrata, que compreende tudo. Apesar disso, a universalidade vem sendo tomada como uma verdade pouco discutida. Por exemplo, a Classificação Decimal de Dewey foi construída "[...] sob a inquestionável presunção de que a universalidade não é apenas desejável, mas necessária. Essa universalidade caracteriza-se pelo foco em favor da semelhança, não da diferença e diversidade" (OLSON, 2002, p. 18).

O item 2 do núcleo axiológico da IFLA seria mais representativo se mencionasse a missão do bibliotecário ao promover o acesso e a apropriação de informações levando em consideração os interesses especiais dos usuários de uma biblioteca.

Interesse: [...] 2. Aquilo que é útil, de importância concreta. 3. Qualidade do que prende a atenção. [...] 7. O que é bom, importante para algo ou alguém (interesse nacional, interesse da comunidade). 8. Atenção inspirada pela curiosidade. 9. Empenho, cuidado, diligência a favor de algo ou alguém. 10. Sentimento que nos inspira cuidado de uma pessoa ou de uma coisa (DICIONÁRIO..., 2014). 
Especial: 1. Que não é geral, mas específico, particular. 2. Que é exclusivo para uma pessoa ou um grupo de pessoas. 3. Que é próprio de uma espécie. 4. Que tem aplicação específica; Específico; Peculiar. 5. Que é fora do comum. 6. Que tem um significado particular (para alguém); Extraordinário. 7. Que oferece vantagens que não são comuns. 8. Diz-se de pessoa com necessidades especiais. 9. Diz-se do que é voltado para o estudo de aspectos específicos de uma área de conhecimentos (DICIONÁRIO..., 2014).

Afirmar que nosso foco estaria naquilo que é útil, de importância concreta e que não é geral, mas específico, particular significa que as necessidades informacionais das comunidades de usuários de uma determinada biblioteca guiarão a atuação dos seus bibliotecários, influenciando nas decisões relacionadas tanto à formação de coleções e representação de assunto como ao ambiente físico e ações culturais.

Consta no núcleo axiológico da IFLA que as pessoas necessitam do acesso não só universal mas também equitativo à informação.

Equidade: 1. Reconhecimento de que os direitos são iguais para todos, expresso em julgamento, ação, atitude etc.; EQUIVALÊNCIA; IGUALDADE. Antôn.: diferenciação, distinção. 2. Característica de quem ou do que revela senso de justiça, imparcialidade; ISENÇÃO; NEUTRALIDADE. Antôn.: iniquidade, injustiça. 3. P.ext. Lisura, correção no modo de agir ou opinar; HONESTIDADE; INTEGRIDADE (DICIONÁRIO..., 2014).

Para o contexto da representação de assunto, a definição de equidade deveria englobar apenas o conceito de equivalência, pois o conceito de igualdade ou o reconhecimento de que os direitos são iguais para todos anula a importância dos interesses especiais de cada comunidade de usuários e desconsideraria a presença do outro no catálogo da biblioteca. Em síntese, para a representação de assunto, equidade significaria fazer os mesmos esforços para dar voz às várias comunidades que utilizam a biblioteca. A conotação imparcialidade na atuação bibliotecária, principalmente na representação de assunto, é um mito e evoca a crença na neutralidade.

Neutralidade: 1. Qualidade ou condição de quem se mantém neutro. 2. Qualidade do que ou de quem revela imparcialidade. [...] (DICIONÁRIO..., 2014).

A neutralidade não se configuraria como algo almejado pela representação de assunto simplesmente porque não é um conceito aplicável a um processo que envolve escolhas e tomadas de decisões constantes por parte do bibliotecário. 


\subsection{A quem é dado o direito de falar?}

Dentre as diversas seções que compõem a IFLA, destacaremos a Seção de Classificação e Indexação, cujo objetivo é atuar como um foro para os produtores e usuários dos instrumentos de classificação e indexação, mediando a troca internacional de informações sobre os métodos de promoção de acesso por assunto.

Os interesses da Seção de Classificação e Indexação envolvem desde a busca de padronização da utilização dos instrumentos de classificação e indexação pelas instituições que criam ou importam registros bibliográficos, até a orientação e desenvolvimento de pesquisas sobre assunto e divulgação dos seus resultados. Nesse contexto, alguns profissionais têm autoridade para criar, atualizar e avaliar instrumentos de padronização, enquanto outros têm autoridade para aplicá-los.

Houve alguns eventos importantes até a divulgação do relatório final do modelo conceitual FRSAD em 2010, os quais se encontram sintetizados no panorama histórico a seguir:

1997: Um grupo de estudiosos da IFLA desenvolve um modelo conceitual definindo as entidades e os relacionamentos existentes no universo bibliográfico, denominado Functional Requirements for Bibliographic Records (FRBR);

1999: A IFLA estabelece um grupo de estudos para aprofundar os trabalhos do FRBR no tocante às entidades descritas nos registros de autoridades ${ }^{5}$ e, então, desenvolver um modelo conceitual voltado aos registros de autoridade, denominado Working Group on Functional Requirements and Numbering of Authority Records (FRANAR);

2004: O FRANAR apresenta o modelo conceitual Functional Requirements for Authority Data (FRAD), cuja principal função é "[...] fornecer uma estrutura de análise dos requisitos necessários ao tipo específico de dado de autoridade que ampara tanto $\mathrm{o}$ controle de autoridade quanto $\mathrm{o}$ compartilhamento internacional de dados de autoridade. O foco do modelo está nos dados independentemente de como eles podem ser apresentados" (FRSAD, 2010, p. 6);

2005: A seção de Classificação e Indexação da IFLA estabelece - Working Group on the Functional Requirements for Subject Authority Records (FRSAR) com o objetivo de aprofundar as reflexões sobre os dados de autoridade de assunto;

2009: O FRSAR divulga o esboço do modelo conceitual FRSAD com o objetivo de receber comentários e sugestões;

\footnotetext{
${ }^{5}$ Nesse contexto, dados de autoridade consistem "[...] no conjunto de informações sobre uma pessoa, família, pessoa jurídica ou obra cujo nome seja utilizado como base para um ponto de acesso controlado de citações bibliográficas ou registros de um catálogo de biblioteca ou arquivo bibliográfico" (FRSAD, 2010, p. 6).
} 
2010: O modelo conceitual FRSAD é disponibilizado pela IFLA e publicado pela editora De Gruyter Saur como uma das obras das IFLA Series on Bibliographic Control.

O histórico da criação do modelo conceitual FRSAD demonstra que seu processo de construção foi cuidadoso, aberto e transparente. Entretanto, não temos maiores informações sobre até que ponto intervenções, seja algum comentário ou sugestão, de pessoas ou instituições que não pertencem à comunidade da IFLA tenham sido levadas em consideração. Caso isso tenha ocorrido, a IFLA teria, de fato, dado voz às pessoas fora do mainstream da Biblioteconomia em sua iniciativa. Mesmo assim, o direito de falar teria sido concedido às pessoas que compreendem a língua inglesa e têm acesso às publicações da IFLA, mas essa já é uma outra questão.

\subsection{Situações que incitaram o discurso}

Discussões que envolvem a representação de assunto em bibliotecas são temas recorrentes em eventos científicos e profissionais, edições de diversos periódicos e livros porque tratam do cerne da atuação bibliotecária: a organização da informação. Ocorre que a maneira pela qual se realiza o processo de representação de assunto é, por natureza, subjetiva e apenas isso já seria motivo suficiente para estimular a produção de diferentes discursos, oficiais ou não, sobre tal processo.

Os instrumentos utilizados para realizar a representação de assunto, a adaptação ou mesmo a tradução deles para aplicação em bibliotecas são questões que têm motivado muitas discussões. Por outro lado, observamos que, no tocante às ocorrências de substitutos documentais contendo algum preconceito, existem poucos materiais para uma fundamentação teórica e menos ainda para abordagens práticas. Tal evidência leva-nos a crer que, provavelmente, os bibliotecários não acreditem ou não valorizem o fato de que esses substitutos documentais possam causar prejuízos a algumas comunidades de usuários e, talvez, até afastá-la da biblioteca.

Uma outra justificativa para a escassez dessa temática na literatura seria a adoção de diferentes tradições de pesquisa em representação de assunto e, além disso, a constatação de que diferentes línguas usam termos diferentes para discutir dilemas iguais ou semelhantes dentro de uma área do conhecimento. Por esse motivo, tentativas de promover um diálogo internacional, como os FRSAD, são imprescindíveis para a representação de assunto.

Dito isso, destacamos que, em princípio, não houve alterações no universo bibliográfico por causa da publicação dos FRSAD. O que a denominada "família FRBR" (FRBR, FRAD e FRSAD) fez foi apresentar ao

6 Não podemos deixar de mencionar a existência da Resource Description and Access (RDA) que "[...] é uma aplicação dos modelos conceituais FRBR e FRAD. A RDA não é, em si mesma, um modelo conceitual, mas, antes, um conjunto de instruções práticas baseadas nos modelos FRBR e FRAD. Estes modelos 
mundo uma "[...] estrutura sistemática e coerente para a compreensão da natureza desses dados. A estrutura também proporciona uma terminologia e uma linguagem conceitual comuns e de fácil reconhecimento internacional" (OLIVER, 2011, p. 34).

Oliver (2011) ressalta que a mudança de perspectivas almejada por esses modelos conceituais focaliza as necessidades de quem utilizará os dados bibliográficos, os usuários, e a soma de dados bibliográficos e de autoridades em grandes catálogos e bases de dados, não em registros catalográficos isolados.

Essas novas perspectivas retomam antigas discussões sobre a representação de assunto, como a presença de comunidades de usuários nas bibliotecas e não de apenas um público homogêneo, e a cooperação e adaptação local dos registros catalográficos.

\subsection{Campo prático no qual o discurso é desenvolvido}

Nos FRBR, as entidades ${ }^{7}$ foram divididas em três grupos e, posteriormente, cada um foi aprofundado por um modelo conceitual específico.

Os FRBR são responsáveis por oferecer orientações sobre o Grupo 1, no qual as entidades são definidas como produtos de esforços intelectuais ou artísticos que são nomeados ou descritos nos registros bibliográficos, quais sejam, obra ${ }^{8}$, expressão ${ }^{9}$, manifestação ${ }^{10}$ e item ${ }^{11}$.

Os FRAD aprofundaram as orientações sobre o Grupo 2, em que as entidades são aquelas responsáveis pelo conteúdo intelectual e artístico, a produção física e disseminação ou custódia das entidades do Grupo 1. As entidades que compõem o Grupo 2 são: pessoa ${ }^{12}$, coletividade (entidade) ${ }^{13}$ e família ${ }^{14}$.

Os FRSAD oferecem orientações sobre o Grupo 3, no qual as entidades representam um grupo adicional de entidades que atuam como assuntos das obras: conceito ${ }^{15}$, objeto ${ }^{16}$, evento ${ }^{17}$ e lugar $^{18}$.

Os especialistas responsáveis pela criação dos FRSAD foram divididos em dois grupos: ao primeiro subgrupo coube a tarefa de relatar as ações dos usuários em sua busca de documentos (i.e., recuperação da informação por assunto); o segundo subgrupo ficou

moldaram a estrutura da RDA e influenciaram a linguagem empregada nas instruções" (OLIVER, 2011, p. 17).

7 Entidade: Algo que possui um caráter unitário e autônomo; algo que tem existência independente ou separada; uma abstração, conceito ideal, objeto de pensamento ou transcendental.

${ }^{8}$ Obra: Criação intelectual ou artística distinta (isto é, o conteúdo intelectual ou artístico).

${ }^{9}$ Expressão: Realização intelectual ou artística de uma obra.

${ }^{10}$ Manifestação: Concretização física de uma expressão de uma obra.

${ }^{11}$ Item: Exemplar individual de uma manifestação.

${ }^{12}$ Pessoa: Indivíduo ou uma identidade individual estabelecida ou adotada por um indivíduo ou grupo

${ }^{13}$ Coletividade (entidade): Organização ou grupo de pessoas e/ou organizações que se identifica por determinado nome e atua, ou pode atuar, como uma unidade

${ }^{14}$ Família: Duas ou mais pessoas relacionadas pelo nascimento, casamento, adoção ou outro estado legal semelhante, ou que, de outro modo, se apresentam como uma família

${ }^{15}$ Conceito: Noção ou ideia abstrata

${ }^{16}$ Objeto: Coisa material

${ }^{17}$ Evento: Ação ou ocorrência

${ }^{18}$ Lugar: Localização, espaço (MulDiCat, 2012). 
responsável por explorar as entidades de assunto e seus relacionamentos (i.e., processo de representação do assunto), inclusive as postuladas pelos FRBR.

\subsection{Quem tem acesso ao discurso?}

Para esse modelo conceitual, os usuários dos dados de autoridade de assunto são os profissionais da informação que criam e mantêm tais dados, os que criam e mantêm os metadados, os intermediários (i.e., bibliotecários de referência) e os usuários finais. Um exemplo de como os usuários finais teriam acesso ao conteúdo do modelo ou quais ações poderiam ser promovidas nesse sentido não foram apresentados.

No Brasil, atualmente, quem tem acesso a esse discurso são as pessoas interessadas em representação de assunto, que utilizam o website da IFLA e têm proficiência em língua inglesa.

\subsection{Posicionamentos em que o texto coloca seus sujeitos}

O foco do modelo FRSAD está no aboutness (a obra 'tem como assunto...' - relação definida nos FRBR") (FRSAD, 2010, p. 10).

Há outras abordagens no tocante à representação de assunto que poderiam ter sido escolhidas para orientar esse modelo conceitual, mas, ao optar por aboutness ${ }^{19}$, o modelo posiciona-se: 0 assunto de um documento é sobre um tópico específico.

O próprio texto esclarece esse posicionamento quando diz que, em relação a aboutness, haveria dois caminhos a seguir: o nominalismo (ou idealismo, segundo Birger Hjørland), que afirma que não é possível que um documento "tenha assuntos" ou "seja sobre um assunto":

[...] aboutness não deveria ser considerado como uma propriedade das obras, mas sim como uma relação construída por uma pessoa específica em um período específico entre um conjunto específico de obras e uma expressão linguística específica (por exemplo: um nome ou um rótulo) (FRSAD, 2010, p. 11).

Por sua vez, o realismo considera que os assuntos dos documentos existem separadamente das expressões linguísticas utilizadas para comunicá-los. Os FRSAD tentam isentar-se quando mencionam a existência de outros pontos de vista sobre a questão do aboutness, mas não nos dizem quais seriam eles.

\footnotetext{
${ }^{19}$ A literatura que trata do aboutness também discute o ofness. Ofness pode ser entendido como o assunto de um tópico específico, geralmente utilizado na indexação de imagens (i.e, são atribuídas diferentes tags a uma imagem publicada em uma rede social que vão desde descrições mais amplas da imagem até especificações de onde a foto foi tirada ou mesmo o que ela significa para o autor). "Uma pintura do pôr-do-sol sob São Francisco [...] pode ser analisada como sendo (genericamente) 'de' pores-do-sol e (especificamente) 'de' São Francisco, mas também 'sobre' a passagem do tempo" (FRSAD, 2010, p. 11). Os FRSAD podem ser aplicados a situações em que as declarações de ofness compõem as representações de assunto.
} 
Vejamos a afirmação a seguir:

Provavelmente seja justo dizer que a maioria das pessoas envolvidas nas tarefas de criação de esquemas de classificação bibliográfica, na indexação de documentos de acordo com tais esquemas e no uso destes como instrumentos para encontrar os tipos de documentos desejados, atua de acordo com premissas compatíveis com alguma versão da perspectiva realista (FRSAD, 2010, p. 11).

Sob nosso ponto de vista, o grupo escolheu alguns posicionamentos que moldaram a construção dos FRSAD. Percebemos uma postura filosófica aristotélica (que se vale do paradigma hierárquico) na maneira pela qual o grupo estruturou o seu texto, quando poderia tê-lo feito em outro formato (i.e., mapa conceitual); na perspectiva do aboutness, quando poderia ter escolhido a análise facetada de Ranganathan, por exemplo; e quando se valeu de uma orientação norte-americana voltada para uma reflexão focada na construção de substitutos documentais.

Apesar de ser possível identificar esses ou outros posicionamentos nos FRSAD, o grupo FRSAR afirma que não tomou nenhuma posição filosófica sobre a natureza do aboutness, mas a observou a partir do ponto de vista do usuário.

\subsection{0 que é reconhecido como válido}

Os FRSAD (2010, p. 9, grifos do autor) foram construídos com o objetivo de amparar as seguintes ações dos usuários:

Encontrar um ou mais assuntos e/ou suas designações, que corresponda $(\mathrm{m})$ aos critérios estabelecidos pelos usuários, usando-se atributos e relacionamentos;

Identificar um assunto e/ou suas designações baseando-se em seus atributos ou relacionamentos (i.e., para distinguir entre dois ou mais assuntos ou designações com características similares e para confirmar a adequação do assunto ou da designação);

Selecionar um assunto e/ou sua designação adequada às necessidades do usuário (i.e., escolhê-la ou rejeitá-la baseando-se nas solicitações e necessidades do usuário);

Explorar relacionamentos entre os assuntos e/ou suas designações (i.e., explorar os relacionamentos visando entender a estrutura de um domínio de assunto e sua terminologia).

É na última ação que os FRSAD diferenciam-se dos demais modelos conceituais da família FRBR, conforme demonstra o quadro a seguir: 
Quadro 1 - Ações do usuário

Fonte: FRSAD (2010, p. 35).

\begin{tabular}{l|l|l}
\hline \multicolumn{1}{c|}{ FRBR } & \multicolumn{1}{c|}{ FRAD } & \multicolumn{1}{c}{ FRSAD } \\
\hline Encontrar & Encontrar & Encontrar \\
Identificar \\
$\begin{array}{l}\text { Selecionar } \\
\text { Obter }\end{array}$ & Identificar & Identificar \\
& & Selecionar \\
& $\begin{array}{l}\text { Contextualizar } \\
\text { Justificar }\end{array}$ & Explorar \\
\hline
\end{tabular}

Os criadores dos FRSAD (2010, p. 46, grifos nossos) acreditam que:

[...] 'explorar' é uma generalização de 'contextualizar' e expressa melhor a ação do usuário de browsing, informar-se, tornar-se familiarizado e descobrir.

Segundo o Dicionário Aulete, explorar significa:

[...] 2. Submeter a análise, pesquisa, testes etc.: explorar um novo remédio. 3. Investigar, estudar para conhecer, entender: explorar os mistérios da mente. [...] 6. Desenvolver ou aproveitar o potencial ou a possibilidade de: Com a dança pôde explorar os movimentos do corpo: Explore melhor o seu dom de escrever (grifo nosso em negrito).

O conceito de explorar aqui exposto não é inédito, uma vez que remonta a uma discussão levantada por Cutter quando ele postulou a conveniência do público. Olson (2001, p. 641) explica que "[a] lógica utilizada por Cutter para a criação de um vocabulário controlado introduz uma aparente imposição democrática de que o catálogo deveria ser construído para a conveniência do público ao qual ele serve." Esse público seria composto por um público singular com uma maneira própria de buscar informação.

Cutter empregou a expressão the users nas suas Regras para um Catálogo Dicionário publicadas em 1904. Ao utilizar o artigo the antes do substantivo, o autor dá indícios de que considera a existência de outros grupos de usuário, mas em suas reflexões ele recorre ao conceito do usuário majoritário. Essa perspectiva de comunidade singular exclui aqueles que são diferentes de alguma maneira (OLSON, 2001).

$\mathrm{Na}$ abordagem de Cutter, o usuário já frequenta a biblioteca, então devemos nos perguntar: a qual usuário os FRSAD se referem?

Concluímos que os FRSAD também mencionam o usuário que já frequenta a biblioteca. O próprio modelo afirma que a inspiração para adicionar a tarefa "explorar" às ações dos usuários deu-se a partir de investigações que demonstraram que os usuários valem-se dos metadados dos vocabulários controlados para navegar pelo sistema de 
recuperação da informação, assim como para explorar os relacionamentos entre os termos dos registros bibliográficos. Estratégias para chegar ao usuário que ainda não frequenta a biblioteca não são comentadas.

Para os usuários que já fazem uso da biblioteca, os dados de autoridade de assunto podem ser utilizados para explorar um domínio do conhecimento, por exemplo:

[...] o usuário A está usando os dados de autoridade de assunto para explorar como o domínio \{ciência da computação\} está representado no contexto do American Society for Information Science and Technology (ASIS\&T) Thesaurus (FRSAD, 2010, p. 37).

O modelo não oferece detalhes sobre como seria a exploração de um domínio do conhecimento pelo usuário. Essa é uma iniciativa promissora no sentido de promover espaços de negociação para enxergarse o outro dentro da biblioteca, porque, ao entender que os domínios do conhecimento são construídos, o usuário poderia pensar sobre a sua posição de dominante e, consequentemente, a existência do outro; ou, então, perceber a sua posição de outro e tentar negociar seu direito à voz naquela biblioteca.

\subsection{Conceitos ou objetos que o texto cria}

As orientações dos FRSAD aos bibliotecários no sentido de guiar os usuários a encontrar, identificar, selecionar e explorar os registros bibliográficos tratam de dois aspectos principais: as entidades e os relacionamentos utilizados para representar os assuntos dos documentos. Analisemos a figura a seguir:

Figura 1 - Relações entre os FRSAD e os FRBR (com a inserção da entidade família do FRAD)

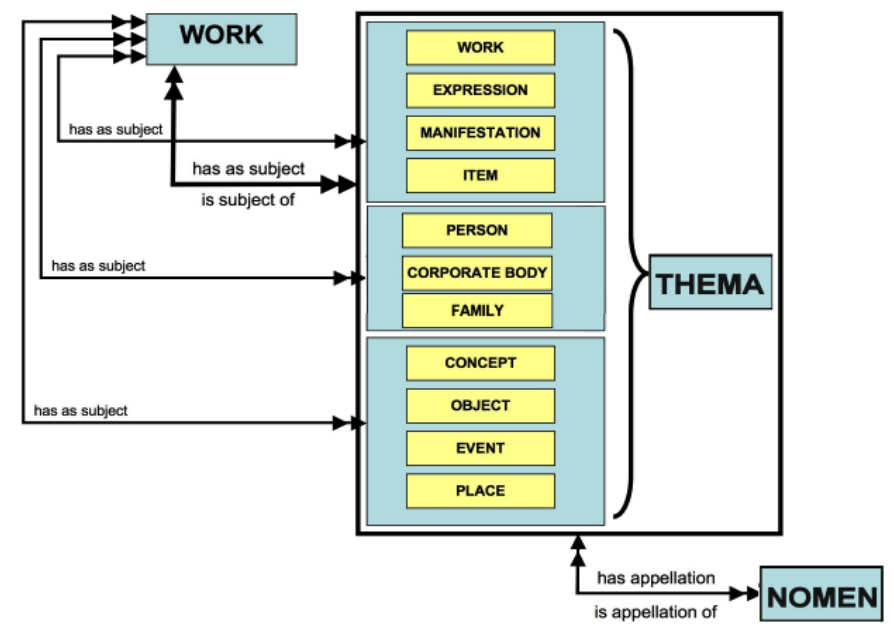

Fonte: FRSAD (2010, p. 15). 
Essa figura demonstra quais são as entidades que poderiam ser utilizadas para representar os assuntos (thema ${ }^{20}$ ) de um documento (work).

\title{
Thema é
}

[...] qualquer entidade usada como assunto de uma obra (FRSAD, 2010, p. 15).

O grupo FRSAR tomou a decisão de evitar qualquer estrutura de subclasses predefinida baseando-se, segundo seus integrantes, em estudos de usuários, revisão de literatura e análises independentes. Segundo esse grupo,

\begin{abstract}
[p]arece não haver uma categorização universal de themas e qualquer tentativa de atestar uma limitaria necessariamente a usabilidade de um modelo geral. Será necessária uma implementação particular para definir as categorias ou tipos de themas. Dessa maneira, as entidades do grupo 3 do FRBR são apenas um conjunto possível (FRSAD, 2010, p. 46, grifo nosso em negrito).
\end{abstract}

Primeiramente, é um avanço depararmo-nos com a declaração de que não existe uma categorização universal. As categorias sintetizam os assuntos de um documento em alguns tópicos de assunto, mas não há um conjunto de categorias fixas e universais para fazê-lo. Nesse sentido, o grupo deu um passo à frente dos outros instrumentos.

Ao apresentar esse argumento, os FRSAD corroboram a crença na necessidade do controle de vocabulário para a representação de assunto. A literatura internacional vem publicando várias pesquisas que investigam a folksonomia ou a utilização de descritores livres para a descrição de documentos, mas esses movimentos não foram mencionados.

Para representar os assuntos utilizando as entidades - obra, expressão, manifestação, item, pessoa, família, coletividade, conceito, objeto, evento, lugar e tempo ${ }^{21}$ - os profissionais valem-se dos nomens.

Nomens são

\footnotetext{
${ }^{20}$ Os termos thema (plural themata ou themas) e nomen (plural nomina ou nomens) foram trazidos do latim porque não têm outros significados na área de organização da informação e não requerem traduções. Ao valerem-se do latim como língua neutra, os criadores dos FRSAD pressupõem isenção quando, na verdade, não estão utilizando uma língua neutra. Melo e Brascher (2014, p. 111) explicam que "[o]utro motivo apontado pelo grupo de trabalho da IFLA foi a necessidade de diferenciar a nova entidade thema da entidade 'conceito' previamente definida no modelo FRBR, considerando-a uma superclasse que inclui todas as entidades FRBR $[\ldots]$ ".

21 As pesquisas posteriores à publicação dos FRBR revelam que "[...] alguns pesquisadores focaram nas entidades do Grupo 3 e, particularmente, no fato de que tempo não está incluso [como uma entidade deste Grupo]" (FRSAD, 2010, p. 40). Tempo figura como uma categoria fundamental quando se tem como objetivo representar diferentes abordagens de um mesmo assunto. Por exemplo, os conceitos gregos de chronos (tempo cronológico) e kairos (tempo baseado em eventos) veiculam diferentes conceitos de tempo.
} 
[...] qualquer sinal ou sequência de sinais (caracteres alfanuméricos, símbolos, som etc.) pelo qual um thema é conhecido, referem-se ou dirigem-se a ele (FRSAD, 2010, p. 15).

Cada thema possui seus atributos, que variam de acordo com o contexto da obra que está sendo representada. Os FRSAD consideram como atributos mais gerais os tipos de thema e notas de escopo ${ }^{22}$. Os tipos de thema são as categorias às quais os nomens pertencem e dizem respeito às onze entidades do FRBR.

No Apêndice $B$ dos FRSAD, o grupo menciona algumas categorias, como tópico, nomes pessoais (como assunto), nomes coletivos (como assunto), geografia, períodos, títulos e eventos, que pertencem à lista de cabeçalhos de assunto facetada Faceted Application of Subject Terminology.

As medidas de recuperação da informação especificidade $\mathrm{e}$ exaustividade vêm à tona quando os $\operatorname{FRSAD~(2010,~p.~26)~mencionam~}$ que:

[...] um nomen mais complexo [...] com adição de qualificadores deve ser construído quando necessário com o intuito de eliminar ambiguidade.

Nesse momento, os FRSAD poderiam, de fato, ter apresentado uma abordagem diferente dos modelos conceituais existentes e a perspectiva de foco no usuário poderia ter, então, aparecido.

Ambiguidade ocorre na língua natural quando uma palavra ou frase (um homógrafo ou polissêmico) tem mais de um significado. A Figura 2 oferece um exemplo e mostra quanto uma única palavra pode ser usada para representar conceitos bem diferentes.

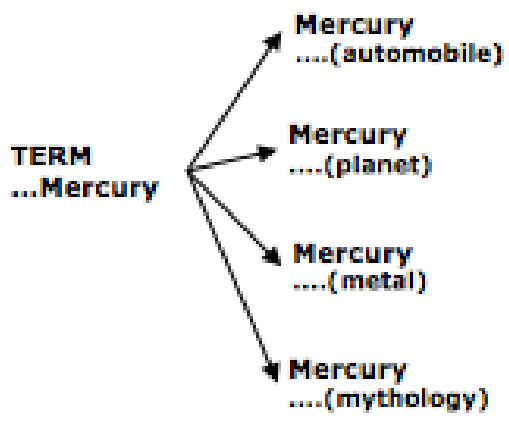

Figura 2: Ambiguidade causada por homógrafo ou polissêmico

Um vocabulário controlado deve contrabalancear os problemas causados pela ambiguidade, assegurando que cada

\footnotetext{
22 Nota de escopo: "Um texto que descreve e/ou define o thema ou especifica o seu escopo no contexto de um sistema de autoridade de assunto particular" (FRSAD, 2010, p. 21).
} 
termo tenha apenas um significado (GUIDELINES..., 2005, p. 13).

Teria sido inovador se os FRSAD houvessem mencionado a possibilidade da utilização de qualificadores de gênero para tratar de forma equitativa e dar visibilidade às questões relacionadas às mulheres, por exemplo.

Para aprimorar o acesso aos assuntos das obras, os FRSAD explicam quais são os possíveis relacionamentos a serem traçados na representação de assunto.

Melo e Brascher (2014) explicam que os FRSAD apresentam três tipos de relacionamentos: obra-to-thema onde uma obra pode ter vários themas e qualquer thema pode ser assunto de várias obras; thema-tonomen onde qualquer thema pode ter múltiplos nomens, mas os nomens devem ser monossêmicos; e thema-to-thema onde as relações estabelecidas entre um thema e outro podem ser hierárquicas, genéricas, todo-parte, de autoridade, poli-hierárquicas e associativas.

O modelo faz um alerta aos bibliotecários para que tomem decisões sobre 0 estabelecimento de relações associativas e seu nível de especificidade em função de um contexto local. Ressaltamos que tais relações oferecem profícuas possibilidades de promover espaços para as diferenças.

Já as relações entre um nomen e outro nomen podem ser de equivalência e todo-parte.

A equivalência de um nomen é um aspecto muito importante do acesso por assunto. Dois nomens são equivalentes se forem designações de um mesmo thema em um contexto monolíngue (FRSAD, 2010, p. 31).

Desse modo, devemos decidir o que consideramos equivalência entre termos em um contexto específico.

Os Guidelines... (2005) já alertavam que é possível estabelecer muitos contextos para a associação de termos pertencentes a diferentes hierarquias, e que as referências de termos relacionados são geralmente feitas entre aqueles que têm uma correspondência etimológica, ou seja, termos que possuem a mesma raiz. Os Guidelines... (2005, p. 53-56) apresentam alguns exemplos significativos de relacionamentos entre os termos:

- Processo/Agente (controle de temperatura TR termostato)

- Processo/Contra agente (fogo TR controladores de chamas)

- Ação/Propriedade (limpeza ambiental TR poluição)

- Ação/Produto da ação (lacrimação TR lágrimas)

- Ação/Alvo (encadernação TR livros) 
- Causa/Efeito (patógenos TR infecções)

- Conceito ou objeto/Propriedade (venenos TR toxidade)

- Conceito ou objeto/Origem (método socrático TR civilização grega)

- Conceito ou objeto/Unidades ou mecanismos de medida (corrente elétrica TR amperes)

- Material bruto/Produto (trigo TR farinha)

- Disciplina ou Campo/Objeto ou Praticante (botânica TR plantas)

Os FRSAD (2010) não incluíram os relacionamentos conceito ou objeto/origem e conceito ou objeto/unidades ou mecanismos de medida, mas ressaltaram o relacionamento coisa/suas partes (carro TR motor) quando a parte não estiver apta a compor a relação hierárquica todoparte.

Outras situações em que os Guidelines... (2005) autorizaram a utilização de relações associativas são quando o termo não se enquadraria como um termo geral (patos TR patos de borracha) ou se configura como um antônimo (baixo TR alto).

Eis uma afirmação em que percebemos uma orientação importante para as bibliotecas que prezam pelas necessidades especiais de seus usuários:

Em alguns vocabulários controlados, pode ser considerado aconselhável refinar as referências aos Termos Relacionados com o intuito de explicitar a natureza do relacionamento. Códigos para cada indicador de relacionamento e seus equivalentes podem ser desenvolvidos localmente. Esses códigos locais devem ser claramente explicados e ilustrados na introdução ou documentação do vocabulário controlado impresso ou digital (GUIDELINES..., 2005, p. 57).

Uma ação que promoveria espaços de negociação nos catálogos seriam as equivalências entre nomens em línguas diferentes, desde que traçadas nos termos propostos por Hudon (1997).

\subsection{Consequências que o texto salienta}

Os $\operatorname{FRSAD}(2010$, p. 44) atestam que:

[u]m bom modelo deve admitir múltiplas estruturas orientadas a cada domínio e ser suficientemente flexível para acomodar diferentes implementações. 
Essa declaração reflete uma preocupação e soa inclusiva, mas como um modelo faria isso sem tentar universalizar as questões que envolvem a representação de assunto? atingido:

O modelo FRSAD (2010, p. 44) afirma que tal objetivo pode ser

[...] somente a partir de um modelo teórico mais abstrato, completamente independente de qualquer implementação que permita o tratamento de atributos e relacionamentos em um nível mais geral.

Entendemos o desejo do grupo em apresentar um modelo teórico abrangente. No entanto, a literatura vem sinalizando que a área de organização da informação esteja, talvez, almejando uma postura mais incisiva no sentido de realçar que os instrumentos de representação de assunto poderiam ser agentes para mudanças e, desse modo, oferecer ferramentas para os bibliotecários darem voz a quem ainda não a possui em sua biblioteca. Usamos o termo ferramentas representando orientações teóricas e concretas; afinal,

[t]ornar as fronteiras de um sistema permeáveis não consiste somente em cruzar vocabulários de uma mesma área ou cruzar barreiras linguísticas. Isso também pode ocorrer quando suplementos ou variantes linguísticas são desenvolvidas para ampliar e adaptar os padrões mainstream de acesso de assunto já existentes (OLSON, 2002, p. 108).

\subsection{Correlações com outras declarações}

Durante o close reading, percebemos que as pessoas envolvidas na criação dos FRSAD tenham provavelmente tentado identificar binários presentes nos modelos conceituais tradicionais. Nesse caso, o dominante seria a estruturação tradicional dos modelos que tratam de questões da representação de assunto e o outro seria o novo conceito de modelo conceitual focado no usuário que se pretende englobar nos FRSAD.

Apesar disso, para esta análise, os FRSAD não se diferenciam substancialmente em sua estrutura e exemplos de modelos tidos como mais tradicionais. As Diretrizes para a Construção, Formato, e Administração de Vocabulários Controlados Monolíngues (GUIDELINES..., 2005) são um bom exemplo.

\subsection{Declarações que o texto exclui}

O texto não menciona que durante o processo de representação de assunto os nomens podem veicular biases terminológicas ou que os relacionamentos entre os themas e os nomens podem ser construídos sob biases. Aliás, a discussão da questão das biases não existe nos FRSAD. 
Não encontramos exemplos extraídos da Classificação Decimal Universal, que é um esquema de classificação amplamente utilizado.

Mencionamos a questão dos exemplos, pois a nossa expectativa era encontrar exemplos provenientes de áreas que envolvessem questões delicadas, já que os FRSAD se dizem orientados às necessidades dos usuários. Afinal, geralmente, representar assuntos provenientes das Ciências Exatas e Biológicas não requer tantas interpretações que envolvem os valores éticos e os preconceitos do bibliotecário quanto das Ciências Humanas e Sociais.

É importante ressaltar que os criadores dos FRSAD compõem um grupo experiente e multicultural. Assim sendo, podemos afirmar que esses pesquisadores sabem da existência de discussões sociais na representação de assunto e, mesmo assim, propuseram exemplos simples e sem maiores implicações sociais.

A autoridade da diretoria da biblioteca não foi mencionada e, por esse motivo, não se discutiu que as decisões administrativas tomadas nesse patamar influenciam diretamente a representação de assunto (i.e., número de bibliotecários atuando na seção, convênios para importação de registros catalográficos, convênios com bases de dados etc.).

Para criar catálogos que abram espaços de negociação, teremos que contar com a possibilidade de utilizarmos mais de uma linguagem de indexação e sistema de classificação; precisaremos também de uma equipe de catalogadores, classificadores e indexadores comprometidos, um serviço de referência estruturado e um acervo multicultural e apropriado. Todos esses quesitos, que envolvem custos, estão relacionados à diretoria da biblioteca.

As presunções destacadas neste artigo compõem o discurso dos FRSAD. Podemos considerar que essas presunções figuram como biases inerentes a esse recurso teórico da área de organização da informação.

As biases percebidas nos FRSAD foram:

a) presença do paradigma do usuário majoritário defendido por Cutter, ou seja, que os usuários almejados já frequentam a biblioteca e têm necessidades informacionais semelhantes;

b) usuário majoritário pertencente ao mainstream;

c) não valorização de que os relacionamentos entre nomens e entre themas poderiam ser usados para negociarmos um espaço para aquelas comunidades que compõem o outro na nossa biblioteca;

d) falta de referência à existência de biases terminológicas na representação de assunto e como isso pode causar prejuízos aos usuários;

e) inovam ao mencionar ação "Explorar", mas não exemplificam como seria essa exploração de um domínio do conhecimento pelo usuário;

f) a autoridade da diretoria da biblioteca não foi mencionada;

g) omissão dos seus posicionamentos filosóficos. 
Por outro lado, os FRSAD:

a) negaram a existência de categorias universais;

b) alertaram sobre a importância do estabelecimento de relações associativas e seu nível de especificidade em função de um contexto local;

c) mencionaram sem, contudo, fundamentar com exemplos ou com uma reflexão teórica mais profunda, a necessidade de que as suas diretrizes sejam adaptadas localmente para servirem como instrumento para representação de assunto.

\section{Considerações finais}

Conforme prevíamos, confirmamos a impossibilidade da criação de modelagens conceituais ou instrumentos de representação de assunto facilmente aplicáveis ou teoricamente completos e transparentes, mas tentativas neste sentido são válidas e frutíferas.

Um modelo conceitual como o dos FRSAD, publicado no contexto da "família FRBR" e coordenado por um grupo multicultural gerenciado pela IFLA, poderia ter deixado claras as suas posições filosóficas e epistemológicas, uma vez que elas estão implícitas no texto. Tais posicionamentos, adotados na composição dos FRSAD, agem como mecanismos de poder e afetam diretamente a atuação dos bibliotecários na representação de assunto.

Ao seguirem a estrutura entidade-relacionamento advinda da Ciência da Computação e valeram-se, implicitamente, da concepção aristotélica inerente aos postulados de Cutter, os FRSAD assumem uma postura aristotélica quando recorrem à supremacia da estrutura hierárquica para a organização do texto. Ao fazer isso, esse modelo conceitual não arriscou em inovar e acolheu uma presunção já discutida por Olson (1999), ou seja, a necessidade de hierarquização para tratar as questões de representação de assunto.

O modelo segue uma tradição norte-americana na formulação de diretrizes que garantam uma função aplicada. Guimarães (2008, p. 82) explica que essa linha de abordagem, denominada subject cataloguing, foi influenciada pela Escola de Chicago e "[...] decorreu diretamente dos princípios de catalogação alfabética de Cutter e da tradição de cabeçalhos de assunto da Library of Congress, cuja ênfase reside no catálogo enquanto produto do tratamento da informação em bibliotecas." Não há problemas em relação a essa postura quando o modelo não assume a pretensão de apresentar um panorama mais teórico sobre o tema.

Criamos a expectativa de que os FRSAD fariam asserções teóricas mais profundas. Entretanto, o que percebemos foi uma apresentação muito bem organizada sobre entidades e relacionamentos, mas com poucas orientações específicas em relação às comunidades de usuários, que seriam o foco deste modelo. Por vezes, o modelo menciona que deve haver uma adaptação das entidades e dos relacionamentos às 
necessidades dos usuários locais sem mostrar, todavia, exemplos de como isso poderia ocorrer.

Por fim, recomendamos o método Desconstrução em documentos textuais advindos de contextos teóricos para a área de Biblioteconomia e Ciência da Informação. É importante dizer que as técnicas close reading e iteração mostraram-se confiáveis ao lidarmos com declarações textuais, além de salientarem o quão ingênua uma revisão de literatura ou uma análise de discurso pode ser quando os autores não se mostram cientes da subjetividade desses processos.

\section{Referências}

ASHCROFT, B.; GRIFFITHS, G.; TIFFIN, H. Post-colonial studies: the key concepts. 2. ed. London: Routledge, 2007. (Routledge Key Guides).

BARITÉ, M. La garantía literaria como herramienta de revisión de sistemas de organización del conocimiento: modelo y aplicación. 2011. 377f. Tese (Doutorado em Informação Científica) - Facultad de Comunicación y Documentación, Universidad de Granada, Granada, 2011.

CALÁS, M. B.; SMIRCICH, L. Voicing seduction to silence leadership. Organization Studies, New York, v. 12, n. 4, p. 567-602, 1991.

CORNELL, D. The philosophy of the limit. New York: Routledge, 1992.

DICIONÁRIO Aulete: o dicionário da língua portuguesa na internet. Disponível em: <http://www.aulete.com.br/>. Acesso em: 22 fev. 2014.

FUNCTIONAL REQUIREMENTS FOR SUBJECT AUTHORITY DATA (FRSAD). $A$ conceptual model. Netherlands: IFLA, 2011. Disponível em: <http://www.ifla.org/node/5849>. Acesso em: $11 \mathrm{dez} .2013$.

GUIDELINES for the construction, format, and management of monolingual controlled vocabularies. Maryland: NISO Press, 2005.

GUIMARÃES, J. A. C. A dimensão teórica do tratamento temático da informação (TTI) no universo científico da International Society for Knowledge Organization - ISKO. Revista Ibero-americana de Ciência da Informação, Brasília, v. 1, n. 1, p. 77-99, 2008.

HUDON, M. Multilingual thesaurus construction: integrating the views of different cultures in one gateway to knowledge and concepts. Knowledge Organization, Würzburg, v. 24, n. 2, p. 84-91, 1997.

INTERNATIONAL FEDERATION OF LIBRARY ASSOCIATIONS AND INSTITUTIONS (IFLA). [Website]. Disponível em: <http://www.ifla.org/about/more>. Acesso em: 10 dez. 2013.

KAIN, P. How to do a close reading. 1998. Disponível em: <http://www.fas.harvard.edu/ wricntr/documents/CloseReading.html>. Acesso em: 22 ago. 2012. 
McClenNEN, S. A. How to do a close reading. 2001. Disponível em: <http://www.personal.psu.edu/users/s/a/sam50/closeread.htm>. Acesso em: 30 jul. 2012.

MELO, M. A. F.; BRÄSCHER, M. Requisitos Funcionais para Dados de Autoridade Assunto (FRSAD): entidades, atributos e relacionamentos. Revista Digital de Biblioteconomia e Ciência da Informação, Campinas, v. 12, n. 2, p. 102-119, 2014.

MILANI, S. O. Biases na representação de assunto: uma perpectiva a partir da literatura internacional de Biblioteconomia e Ciência da Informação. Brazilian Journal of Information Science: Research Trends, Marília, v. 9, n. 1, 2015.

MILANI, S. O.; GUIMARÃES, J. A. C.; OLSON, H. A. Bias in subject representation: convergences and divergences in the international literature. In: INTERNATIONAL ISKO CONFERENCE, 13., 19-22 may 2014. Proceedings... Knowledge Organization in the 21st Century: between historical patterns and future prospects. Kraków, Poland. Würzburg: Ergon, 2014. p. 335-342. (Advances in Knowledge Organization, 14).

MULDICAT: Multilingual Dictionary of Cataloguing Terms and Concepts. Netherlands: $\quad$ IFLA, $2012 . \quad$ Disponível em: $<$ http://www.ifla.org/publications/multilingual-dictionary-of-cataloguingterms-and-concepts-muldicat>. Acesso em: 25 fev. 2016.

OLIVER, C. Introdução à RDA: um guia básico. Brasília: Briquet de Lemos/Livros, 2011.

OLSON, H. A. Exclusivity, teleology and hierarchy: our Aristotelian legacy. Knowledge Organization, Würzburg, v. 26, n. 2, p. 65-73, 1999.

OLSON, H. A. Patriarchal structures of subject access and subversive techniques for change. Canadian Journal for Information and Library Science, Toronto, v. 26, n. 2/3, p. 1-29, 2001.

OLSON, H. A.; FOX, M. J. Feminist Epistemologies and Knowledge Organization. In: SMIRAGLIA, R. P.; LEE, H.-L. (Ed.). Cultural frames of knowledge. Würzburg: Ergon, 2012. p. 79-97.

OLSON, H. A.; SCHLEGL, R. Standardization, objectivity, and user focus: a meta-analysis of subject access critiques. Cataloging \& Classification Quarterly, New York, v. 32, n. 2, p. 61-80, 2001.

OLSON, H. A. The power to name: locating the limits or subject representation in libraries. Dordrecht: Kluwer Academic Publisher, 2002.

OLSON, H. A. The power to name: marginalizations and exclusions of subject representation in library catalogues. 1996. 432f. Tese (Doutorado em Library and Information Studies) - University of Wisconsin-Madison, Madison, Wisconsin, United States, 1996.

SEVERINO, A. J. Metodologia do trabalho científico. 23. ed. São Paulo: Cortez, 2007. 